\title{
CD5-mediated inhibition of TCR signaling proceeds normally in the absence of SHP-1
}

\author{
BAOXIA DONG ${ }^{1 *}$, ALLY-KHAN SOMANI ${ }^{2,4 *}$, PAULE. LOVE ${ }^{3}$, XUAN ZHENG ${ }^{1}$, \\ XIEQUN CHEN ${ }^{1}$ and JINYI ZHANG ${ }^{2}$ \\ ${ }^{1}$ Department of Haematology, Xijing Hospital, The Fourth Military Medical University, Xi'an, Shaanxi 710032, P.R. China; \\ ${ }^{2}$ Lunenfeld-Tanenbaum Research Institute, Mount Sinai Hospital, Toronto, ON M5G 1X5, Canada; \\ ${ }^{3}$ The Laboratory of Mammalian Genes and Development, National Institute of Child Health and \\ Human Development, National Institutes of Health, Bethesda, MD 20892, USA
}

Received October 10, 2015; Accepted April 6, 2016

DOI: $10.3892 /$ ijmm.2016.2592

\begin{abstract}
The CD5 transmembrane glycoprotein functions as a co-receptor in the signaling pathway linking T-cell antigen receptor (TCR) engagement to activation and differentiation. Although CD5 effects on TCR signaling have been shown to be primarily inhibitory, the underlying mechanisms remain unclear. In view of recent data revealing the ability of CD5 to associate with the SHP-1 tyrosine phosphatase, a protein that also downregulates TCR signaling, we examined the role of SHP-1 in modulating CD5 function using thymocytes from SHP-1-deficient viable motheaten $\left(m e^{v}\right)$ mice. The results revealed the association of SHP-1 with CD5 to be markedly increased following TCR stimulation and indicated that this interaction was enhanced by and was dependent on CD5 tyrosine phosphorylation. However, there was no difference of the tyrosine phosphorylation status of CD5 between resting and TCR-stimulated cells in SHP-1-deficient compared to wildtype thymocytes. Lack of SHP-1 activity did not affect the levels of CD5 surface expression, CD5 co-immunoprecipitable tyrosine phosphatase activity and intracellular calcium increase following co-crosslinking of the TCR and CD5. Similarly, an analysis of T-cell thymocyte populations in $m e^{v}$ mice expressing an $\mathrm{H}-\mathrm{Y}$ transgene as well as a construct mediating T-cell
\end{abstract}

Correspondence to: Dr Baoxia Dong, Department of Haematology, Xijing Hospital, The Fourth Military Medical University, Xi'an, Shaanxi 710032, P.R. China

E-mail: dongbaoxia18@163.com

Dr Jinyi Zhang, Lunenfeld-Tanenbaum Research Institute, Mount Sinai Hospital, Toronto, ON M5G 1X5, Canada

E-mail: jinyi@mshri.on.ca

Present address: ${ }^{4}$ Department of Dermatology, Indiana University School of Medicine, Indianapolis, IN 46202, USA

${ }^{*}$ Contributed equally

Key words: T-cell antigen receptor signaling, tyrosine phosphatase, thymic selection, CD5, SHP-1 restricted CD5 overexpression, revealed that the reduction in the positive selection conferred by CD5 overexpression was unaffected by SHP-1 deficiency. CD5 is not a SHP-1 substrate and SHP-1 is not required for and possibly not involved in the CD5-mediated modulation of TCR signaling.

\section{Introduction}

CD5 is a monomeric 67-kDa type I transmembrane glycoprotein belonging to the scavenger receptor cysteine-rich (SRCR) family (1), and is expressed in a variety of immune cells (2). CD5 is expressed at low levels on immature CD4-CD8-(double negative, DN) thymocytes and becomes increasingly expressed on $\mathrm{CD}^{+} \mathrm{CD}^{+}$(double positive, DP) and single positive (SP) $\mathrm{CD}^{+}{ }^{+}$or $\mathrm{CD}^{+}$thymocytes (3). In the periphery, $\mathrm{T}$ cells express high levels of CD5 (4). Although several potential ligands for CD5 have been identified (5-7), the physiologically relevant CD5 interactions with their associated signaling pathways is not completely understood.

CD5 has been shown to physically and functionally associate with the antigen receptor on $\mathrm{T}$ and $\mathrm{B}$ cells (8-10). However, the physiologically relevant and ultimate function of CD5 on antigen receptor signaling remains elusive. Historically, CD5 has been shown to possess a costimulatory function, as cross-linking of CD5 with antibodies enhances TCR-mediated activation, proliferation, increases in intracellular $\mathrm{Ca}^{2+}$, inositol triphosphate, interleukin-2 (IL-2) secretion, and IL-2R expression $(11,12)$. Previous studies, particularly those utilizing the CD5 knockout mice have provided considerable insight into CD5 function. By contrast the studies suggested a primarily negative role for CD5 in antigen receptor-mediated signaling (13), although recent findings demonstrated that soluble human CD5 expressed in mice enhances experimentally induced autoimmune and antitumoral immune responses (14). Furthermore, the ability of CD5 to act as a negative regulator of TCR-mediated signaling has been shown to have a physiological impact on thymocyte development in terms of thymic selection $(15,16)$. The ability of CD5 to attenuate TCR-mediated signals suggests that CD5 is important in T-cell development and represents a mechanism for fine-tuning thymic selection (3). 
Although CD5 does not appear to have any intrinsic catalytic activity, the cytoplasmic domain of CD5 contains Y378, Y429, Y441 and Y463 tyrosine residues and several putative serine/threonine phosphorylation sites (17). Following TCR stimulation the cytoplasmic domain of CD5 becomes rapidly phosphorylated $(15,18)$ and this is thought to recruit other signaling molecules. In particular, tyrosine residues 429 and 441 are embedded in an imperfect immunoreceptor tyrosine-based activation motif (ITAM)-like sequence (19), while tyrosine 378 is contained within an immunoreceptor tyrosine-based inhibitory motif (ITIM)-like sequence (20), suggesting that these sites can act as docking sites for proteins with $\mathrm{SH} 2$ domains. A study on Jurkat T cells has shown that tyrosine 378 in the ITIMlike sequence of CD5 is required for SHP-1 association and is involved in SHP-1 tyrosine phosphatase activity in mediating the downregulatory activity of CD5 (21). Furthermore, a correlation was demonstrated between the phosphorylation state of CD5 and the phosphatase activity of SHP-1, suggesting that CD5 may represent a substrate for SHP-1 activity (22). It has been reported that Lyn-mediated SHP-1 binding to CD5 contributes to resistance to apoptosis of B-cell chronic lymphocytic leukemia cells (23). However, the role of SHP-1 in mediating the negative regulatory effects of $\mathrm{CD} 5$ remains controversial. For example, CD5-deficient T-cell hybridomas transfected with a truncated form of CD5 that retains the ITIM-like sequence (Y378) were unable to negatively regulate TCR responses (16).

To clarify the functional and physiological requirement of SHP-1 in the CD5 signaling pathway, we assessed the ability of CD5 to downregulate TCR signaling and thymic selection in the context of SHP-1 deficiency. The results showed that although SHP-1 associates with CD5, the tyrosine phosphorylation profile of CD5 following TCR stimulation was not different in SHP-1-deficient viable motheaten $\left(m e^{v}\right)$, compared to wild-type thymocytes. The lack of SHP-1 activity also had no impact on the levels of CD5 surface expression, CD5-associated PTP activity, and intracellular calcium mobilization profiles following TCR/CD5 co-crosslinking. Similarly, an analysis of T-cell thymocyte populations in $m e^{v}$ mice expressing an H-Y transgene as well as a construct mediating T-cell-restricted CD5 overexpression, revealed that the reduction in positive selection conferred by CD5 overexpression was unaffected by SHP-1 deficiency. Cumulatively, these observations indicate that CD5 is not an SHP-1 substrate and suggest SHP-1 is not required for and possibly not involved in CD5-mediated downregualation of TCR signaling.

\section{Materials and methods}

Mice. Mice homozygous for the viable motheaten mutation $\left(m e^{v}\right)$ were obtained by mating C57BL/6J $m e^{v /+}$ breeding pairs derived from breeding stock maintained at the Samuel Lunenfeld Research Institute, Mount Sinai Hospital (Toronto, ON, Canada).The study was approved by the local Ethics Committee of Mount Sinai Hospital. Mice carrying an $\mathrm{H}-\mathrm{Y}$-specific TCR transgene, which recognizes the $\mathrm{H}-\mathrm{Y}$ male-specific antigen presented on $\mathrm{H}-2 \mathrm{D}^{\mathrm{b}}(24)$, were crossed with $m e^{v /+}$ heterozygotes/+ heterozygotes and the $\mathrm{H}-\mathrm{Y}$ $\mathrm{TCR} / m e^{v /+}$ progeny selected and backcrossed with $m e^{v} /+$ mice to obtain H-Y TCR/mev homozygotes. For the derivation of CD5 transgenic mice, a huCD2-CD5 transgene was derived as previously detailed by substituting the murine CD5 coding sequence for the TCR $\zeta$ cDNA sequence in the construct §-CT108 (25). Founder lines were identified by Southern blotting, screened for expression of CD5 by Northern blotting and flow cytometry analysis and the mice then backcrossed to C57BL/6J through six generations. The mice were then mated with H-Y TCR transgenic mice to generate H-Y TCR/CD5 transgenics. To derive H-Y TCR/CD5/me $v$ mice, the H-Y TCR/ CD5 transgenics were mated to $m e^{v} /+$ mice and the F1 H-Y TCR/CD5 transgenic viable motheaten heterozygote progeny then backcrossed with $m e^{v} /+$ mice. The mice were typed for expression of the H-Y TCR and CD5 transgenes using PCR amplification with the primer pairs: 5'-CAGACCCTCCT TGATCCTGGCCCTCCAGT-3' (forward) and 5'-CAGTCC GTGGACCAGCCTGATGCTCATGT-3' (reverse); 5'-GGA GCACATCAGAAGGGCTGGCTT-3' (forward) and 5'-CGG AGATCCTTGGGCAGAAGACCTG-3' (reverse), respectively. The PCR amplification cycle (denaturation for $15 \mathrm{sec}$ at $94^{\circ} \mathrm{C}$, annealing for $20 \mathrm{sec}$ at $64^{\circ} \mathrm{C}$ and elongation for $30 \mathrm{sec}$ at $72^{\circ} \mathrm{C}$ ) was repeated 35 times. H-Y TCR and CD5 transgene expression was also confirmed by surface staining of peripheral blood lymphocytes (26). The mice were studied at the ages of 2-3 weeks.

Antibodies and reagents. Antibodies used for these studies included FITC-conjugated anti-CD8 (cat. no. 553031; 1:1,000) and anti-CD5 (cat. no. 553020; 1:1,000) antibodies, PE-conjugated anti-CD4 antibody (cat. no. 557307; 1:1,000), and biotin-conjugated monoclonal rat anti-mouse CD5 (clone 53-7.3; cat. no. 553018; 1:1,000), anti-TCR $(\alpha \beta)$, and anti-CD4 antibodies all obtained from Pharmingen ( $\mathrm{La}$ Jolla, CA, USA). Purified monoclonal rat ant-mouse CD5 (clone 53-7.3) was generously provided by Dr L.A. Herzenberg (Stanford University, Stanford, CA, USA) or purchased from Pharmingen. Rat anti-mouse IgG, goat ant-rat IgG and streptavidin and avidin were obtained from Jackson ImmunoResearch (West Grove, PA, USA). Anti-phosphotyrosine monoclonal antibody 4G10, protein A and sheep anti-mouse antibody conjugated to horseradish peroxidase were purchased from Upstate Biotechnology, Inc. (Lake Placid, NY, USA). Rabbit polyclonal anti-SHP-1 antibody recognizing the tandem $\mathrm{SH} 2$ domains of SHP-1 was generated in the laboratory as previously described (27). Polyclonal anti-CD5 (R5) rabbit serum to the highly conserved peptide sequence, TASHVDNEYSQPPR, in the CD5 cytoplasmic domain was generously provided by Drs Greg Appleyard and Bruce Wilkie (Department of Pathobiology, University of Guelph, Guelph, ON, Canada). Chemicals used for immunoblotting/immunoprecipitation were purchased from Sigma Chemical Corp. (St. Louis, MA, USA).

Cell stimulation, Immunoprecipitation and western blot analysis. Single-cell suspensions of thymocytes (3x107/condition) obtained from wild-type or $m e^{v}$ mice were resuspended in $150 \mu \mathrm{l}$ of phosphate-buffered saline (PBS) and incubated for $30 \mathrm{~min}$ at $4^{\circ} \mathrm{C}$ in the presence or absence of $2.5 \mu \mathrm{g}$ biotin-conjugated anti-mouse TCR antibody. Following several washes to remove any unbound antibody, the cells were resuspended in $40 \mu \mathrm{l} \mathrm{PBS}$ and incubated at $37^{\circ} \mathrm{C}$ for various time points with $50 \mu \mathrm{g} / \mathrm{ml}$ avidin or $25 \mu \mathrm{g} / \mathrm{ml}$ streptavidin. The cells were then pelleted by 30 -sec centrifugation 
and lysed in $400 \mu \mathrm{l}$ of cold lysis buffer supplemented with protease inhibitors [1\% Nonidet P-40, $50 \mathrm{mM}$ HEPES (pH 7.2), $150 \mathrm{mM} \mathrm{NaCl}, 50 \mu \mathrm{M} \mathrm{NaF}, 50 \mu \mathrm{M} 0$-phosphate, $50 \mu \mathrm{M} \mathrm{ZnCl}, 2$ mM EDTA, $2 \mathrm{mM} \mathrm{Na}_{3} \mathrm{VO}_{4}, 2 \mathrm{mM}$ PMSF, $10 \mu \mathrm{g} / \mathrm{ml}$ leupeptin and $10 \mu \mathrm{g} / \mathrm{ml}$ aprotinin] for $30 \mathrm{~min}$ on ice. Nuclei and unlysed cells were removed by centrifugation at $14,000 \mathrm{x}$ for $10 \mathrm{~min}$ at $\sim 4^{\circ} \mathrm{C}$ and protein concentrations were determined by means of the bicinchoninic acid (BCA) assay (Pierce Biochemicals, Rockford, IL, USA). Equal amounts of lysates $(300-500 \mu \mathrm{g})$ were incubated for $2 \mathrm{~h}$ at $4^{\circ} \mathrm{C}$ with the appropriate antibody (anti-CD5, or anti-IgG isotype control) and $30 \mu \mathrm{l}$ of $50 \%$ protein $\mathrm{G}$ Sepharose beads (Pharmacia, Toronto, Canada) was added and the samples agitated at $4^{\circ} \mathrm{C}$ for an additional hour. Immunocomplexes were collected by centrifugation and washed five times in $1 \mathrm{ml}$ of cold lysis buffer and then boiled for $5 \mathrm{~min}$ in reduced SDS-gel sample buffer. The samples were resolved on $10 \%$ sodium dodecyl sulfate-polyacrylamide gel electrophoresis (SDS-PAGE) and transferred onto nitrocellulose membranes (Bio-Rad Laboratories, Mississauga, ON, Canada). Blots were blocked for $\geq 1 \mathrm{~h}$ in TBS-T containing $3 \%$ gelatin or $5 \%$ non-fat milk, and incubated for $1 \mathrm{~h}$ at room temperature with optimal concentrations of the primary antibody [anti-CD5 (R5), antiSHP-1 or anti-phosphotyrosine 4G10]. The blots were then incubated with the appropriate secondary antibody conjugated to horseradish peroxidase and subjected to enhanced chemiluminescence (ECL; Amersham Corp., Arlington Heights, IL, USA). Where indicated, the immunoblots were stripped and reprobed with anti-CD5 or anti-SHP-1 antibody.

Immunocomplex phosphatase activity assay. For analysis of CD5-associated phosphatase activity, anti-CD5 immunoprecipitates were prepared. Briefly, wild-type and $m e^{v}$-derived thymocytes $\left(1 \times 10^{8}\right)$, unstimulated or stimulated with biotinylated antibodies to anti-TCR and anti-CD4 at $10 \mu \mathrm{g} / \mathrm{ml}$ plus streptavidin at $25 \mu \mathrm{g} / \mathrm{ml}$ for $5 \mathrm{~min}$ at $37^{\circ} \mathrm{C}$, were lysed into $400 \mu \mathrm{l}$ of cold lysis buffer, as described earlier, without sodium orthovanadate. An equal amount of lysates was then subjected to CD5 immunoprecipitation using anti-CD5 (53-7.3) antibody or rat anti-mouse IgG isotype control. Immunoprecipitates were incubated at $37^{\circ} \mathrm{C}$ for $90 \mathrm{~min}$ with $1 \mathrm{mM}$ phosphopeptide RRLIEDAEY-pAARG (Upstate Biotechnology, Lake Placid, $\mathrm{NY}$, USA) in $10 \mathrm{mM}$ Tris- $\mathrm{HCl}(\mathrm{pH} 7.4)$ phosphatase buffer. Free phosphate detection was carried out as specified by the manufacturer. To standardize for the non-specific phosphatase the activity associated with $\mathrm{IgG}$, relative phosphatase activity was determined by dividing the measured absorbance values with those from unstimulated $\mathrm{IgG}$ negative controls.

Calcium measurements. Thymocytes $\left(5 \times 10^{6}\right.$ cell $\left./ \mathrm{ml}\right)$ were labeled with Indo-1 $(5 \mu \mathrm{M})$ and incubated at $37^{\circ} \mathrm{C}$ in the dark for $30 \mathrm{~min}$. Thymocytes were washed, resuspended in RPMI-1640 containing 2\% fetal bovine serum (FBS) and $10 \mathrm{mM}$ HEPES (pH 7.4), and incubated on ice with biotinylated anti-TCR alone (2.0 or $0.3 \mu \mathrm{g})$, or in combination with either biotinylated $(2.5 \mu \mathrm{g})$ or non-biotinylated anti-CD5 $(2.5 \mu \mathrm{g})$ for $30 \mathrm{~min}$. After washing, the cells were resuspended in RPMI-1640 buffer at a concentration of $\times 10^{7}$ cells $/ \mathrm{ml}$ and stimulated with streptavidin $(5 \mu \mathrm{g} / \mathrm{ml})$. Goat anti-rat antibody $(16 \mu \mathrm{g})$ was also used to crosslink samples containing non- biotinylated anti-CD5 antibody. The cells were analyzed on a flow cytometer and calcium levels were detected by analysis of the Indo-1 violet-blue fluorescence ratio.

Flow cytometric analysis. Cells (5x106/sample) were resuspended in $100 \mu \mathrm{l}$ immunofluorescent staining buffer (PBS containing $1 \%$ BSA and $0.05 \%$ sodium azide) and incubated with the appropriate fluorochrome-conjugated antibodies (FITC-conjugated anti-CD8 or PE-conjugated anti-CD4) for $30 \mathrm{~min}$ at $4^{\circ} \mathrm{C}$. For CD5 staining, the cells were incubated with biotinylated anti-CD5 for $30 \mathrm{~min}$ at $4^{\circ} \mathrm{C}$, washed and then incubated with FITC-conjugated streptavidin. Stained cells were analyzed using a FACScan flow cytometer with CellQuest software (Becton-Dickinson, San Diego, CA, USA).

\section{Results}

SHP-1 interaction with CD5 is increased following receptor phosphorylation. We previously demonstrated the ability of SHP-1 to associate with CD5 in activated mouse thymocytes, association that was somewhat enhanced following CD5 tyrosine phosphorylation, suggesting that the interaction may be $\mathrm{SH} 2$ domain is mediated (28). Since then there have been several studies supporting this contention. Bikah et al have reported observing CD5 association with SHP-1 in resting but not activated T cells and in BKS-2 B lymphoma cells (29). Sen et al have also reported that phosphorylated CD5 is associated with SHP-1 in B-1 cells (30). Recently, PerezVillar et al have also shown a constitutive association of CD5 with SHP-1 in Jurka T cells and PHA-expanded T lymphoblasts, which increased following TCR stimulation (21). In addition, mapped Tyr-378 in the ITIM-like sequence of CD5 was found to be essential for SHP-1 binding to CD5 in Jurkat T cells (21). However, the association of SHP-1 with CD5 as well as the SH2 mechanism for mediating SHP-1 interaction has been previously addressed $(16,31,32)$. We therefore examined the association profile of SHP-1 and CD5 in resting and TCR-stimulated wild-type thymocytes. Immunoprecipitates of CD5 when immunoblotted with SHP-1 revealed a strong association with SHP-1 following TCR activation (Fig. 1). The association of SHP-1 with CD5 occured rapidly following this stimulation and directly correlated to the level of CD5 phosphorylation (interaction decreased as the level of CD5 was reduced). Thus, association of SHP-1 with CD5 in thymocytes was not constitutive but rather dependent on TCR activation and the level of CD5 tyrosine phosphorylation.

CD5 tyrosine phosphorylation profile is unchanged in SHP-1-deficient thymocytes. Given that the profile of SHP-1 binding to CD5 was found to be dependent on the level of CD5 phosphorylation (Fig. 1), together with recent data demonstrating a correlation between the phosphatase activity of SHP-1 and the status of CD5 phosphorylation (involving SHP-1 as the phosphatase responsible for CD5 dephosphorylation) (22), we addressed whether CD5 is a substrate for SHP-1 activity. Previously it was shown that many molecules representing direct or indirect potential substrates for SHP-1 activity, were either constitutively hyper-phosphorylated and/ or exhibited enhanced and prolonged activation-induced tyrosine phosphorylation profiles in SHP-1 deficient compared 

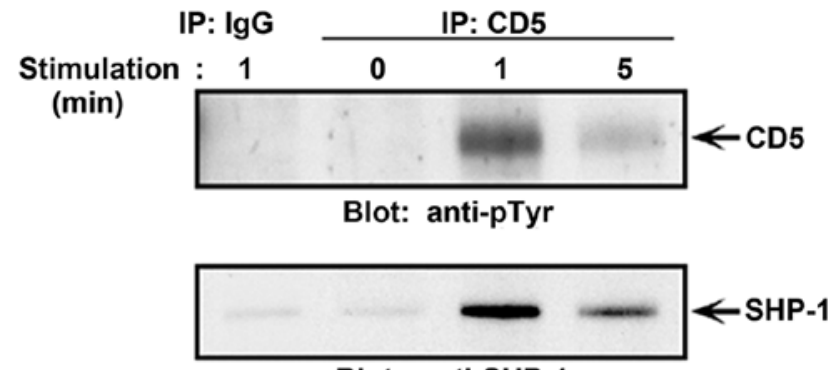

Blot: anti-SHP-1

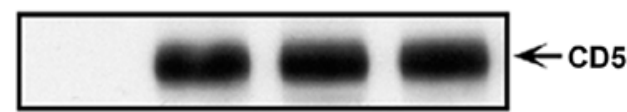

Blot: anti-CD5

Figure 1. SHP-1 interaction with CD5 is increased following receptor phosphorylation. Wild-type $(\mathrm{C} 57+/+)$ thymocytes $\left(3 \times 10^{7}\right)$ were incubated with biotin-conjugated anti-mouse T-cell antigen receptor (TCR) and then stimulated by crosslinking with streptavidin for the indicated times $(0,1$ and $5 \mathrm{~min}$ ). Equalized lysate proteins were then immunoprecipitated with control IgG or anti-CD5 mAb, resolved on $10 \%$ sodium dodecyl sulfatepolyacrylamide gel electrophoresis (SDS-PAGE) and transferred to the membrane. The level of CD5 phosphorylation was detected by blotting with anti-phosphotyrosine antibody (top panel). The level of CD5 and SHP-1 association was determined by stripping and reprobing the blot with anti-SHP-1 (middle panel) or anti-CD5 (bottom panel).

to wild-type cells (28). Of note, the tyrosine phosphorylation status of CD5 in the resting and TCR-stimulated thymocytes from normal compared to SHP-1 deficient $\left(m e^{v}\right)$ mice was unchanged (Fig. 2). The lack of constitutive and hyperphosphorylated CD5 in the context of SHP-1-deficiency, together with a normal phosphorylation profile following TCR stimulation, strongly argues against a role for SHP-1 in the dephosphorylation of CD5.

SHP-1 deficiency does not alter thymic CD5 surface expression. CD5 expression is closely regulated throughout T-cell development. CD5 is expressed at low levels on immature CD4-CD8 (DN) thymocytes and becomes increasingly expressed on $\mathrm{CD}^{+} \mathrm{CD}^{+}(\mathrm{DP})$ and single-positive (SP) $\mathrm{CD} 4^{+}$ or $\mathrm{CD}^{+}$thymocytes (3), with the mature peripheral $\mathrm{T}$ cells expressing high levels (33). Recently, Azzam et al showed that $\mathrm{CD} 5$ expression was regulated by the strength and avidity of TCR signals (3). The lack of any observable differences in the thymic CD5 tyrosine phosphorylation profiles in $m e^{v}$ mice led us to examine thymic CD5 surface expression levels. In contrast to the findings in peripheral $\mathrm{T}$ cells isolated from SHP-1-deficient mice, which express elevated basal levels of CD5 (34), we detected equivalent CD5 surface levels in $m e^{v}$ compared to wild-type thymocytes (Fig. 3). Therefore, the lack of SHP-1 did not affect levels of CD5 surface expression during early T-cell development.

SHP-1 deficiency does not significantly alter CD5-associated PTP activity. Previous studies in the human T-cell Jurkat lymphoma cell line demonstrated a moderate tyrosine phosphatase activity associated with CD5 immunoprecipitates (21). This CD5-associated PTP activity was shown to substantially increase following TCR-stimulation (21). Perez-Villar et al elucidated the molecular basis for this CD5-associated phosphatase activity and attributed this function to the interaction

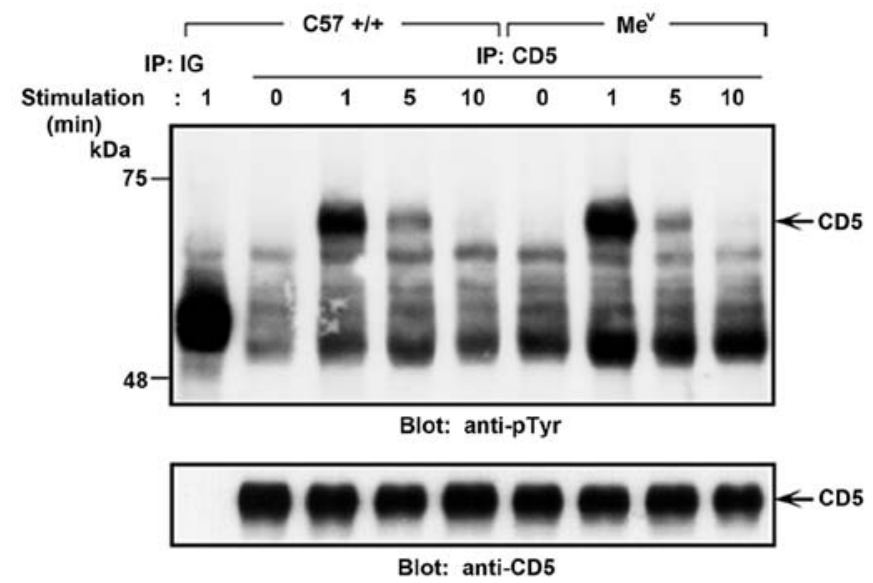

Figure 2. CD5 tyrosine phosphorylation is unchanged in SHP-1-deficient thymocytes. Thymocytes $\left(3 \times 10^{7}\right)$ from wild-type $(\mathrm{C} 57+/+)$ and $m e / m e^{v}\left(\mathrm{Me}^{v}\right)$ mice were incubated with biotin-conjugated anti-mouse T-cell antigen receptor (TCR) and then stimulated by crosslinking with streptavidin for the indicated times $(0,1,5$ and $10 \mathrm{~min})$. Equalized lysate proteins were then immunoprecipitated with control IgG or anti-CD5 mAb, resolved on 10\% sodium dodecyl sulfate-polyacrylamide gel electrophoresis (SDS-PAGE) and transferred to the membrane. The level of CD5 phosphorylation was detected by blotting with anti-phosphotyrosine antibody and the level of CD5 protein was determined by reprobing the blots with anti-CD5 (upper and lower panels, respectively).

of CD5 with SHP-1 but not SHP-2 (21). Supporting this view are recent data by Sen et al, examining CD5-associated PTP activity in wild-type B-1 cells (30). Sen et al also found CD5 to be associated with PTP activity, which could be completely eliminated by the prior immunodepletion of SHP-1 but not SHP-2, supporting the hypothesis that the phosphatase activity associated with CD5 was derived mainly from SHP-1 (30). Given that CD5 is not a direct substrate for SHP-1 action, the functional association of SHP-1 with CD5 supports a model whereby the negative regulatory function of CD5 is mediated by the recruitment of SHP-1 into the antigen-receptor complex $(21,28-30)$. By contrast, Gary-Gouy et al suggest that the effect of CD5, at least, on BCR signaling was independent of SHP-1. In that study, the authors did not show any physical interaction with SHP-1, SHP-2 or SHIP concluding that other inhibitory phosphatases may exist that carry out the negative function of CD5 (31). Given those findings, we examined and compared CD5-associated PTP activity from wild-type and SHP-1-deficient $\left(m e^{v}\right)$ thymocytes. The results showed that SHP-1-deficient thymocytes also retained wildtype compared to CD5-associated PTP activity (Fig. 4). This PTP activity (as in the case of wild-type) increased following TCR stimulation. Therefore, our findings suggested that there is a redundancy with respect to SHP-1 function, or more likely, that there are other phosphatases besides SHP-1 that are responsible for mediating the negative modulatory effects of CD5 in thymocytes.

TCR/CD5-mediated calcium response is dependent on the method of CD5 stimulation. Biochemical observations thus far in SHP-1-deficient thymocytes suggest that CD5 does not require SHP-1 activity, as there were no differences in the CD5 phosphorylation status, CD5 surface expression or CD5-associated PTP activity. However, these findings still do not exclude a possible requirement of SHP-1 in CD5 signaling 

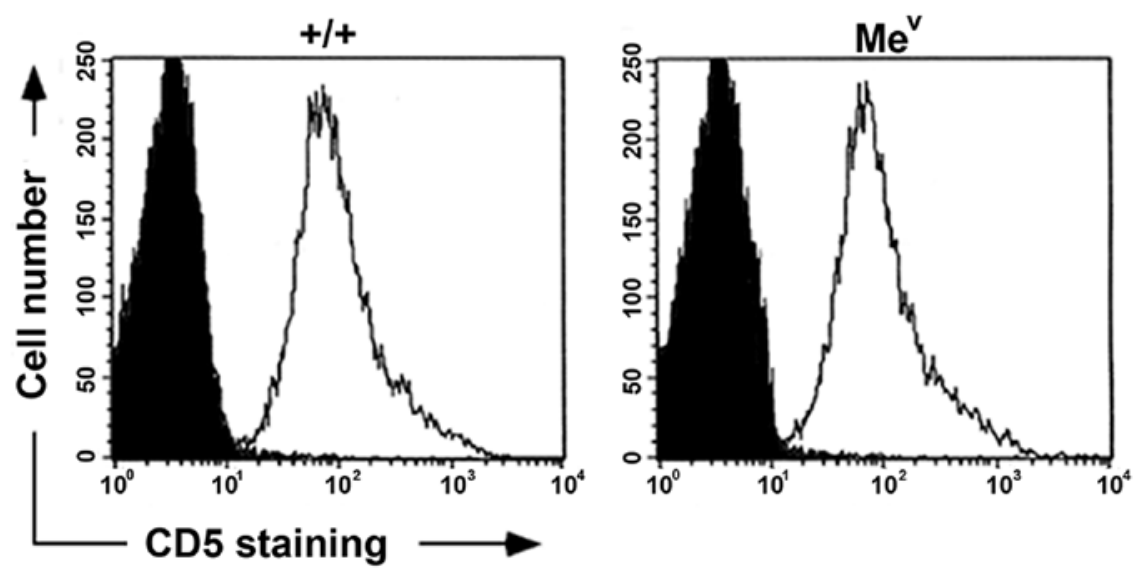

Figure 3. SHP-1 deficiency does not alter thymic CD5 surface expression. Age-matched thymocytes $\left(5 \times 10^{6}\right)$ from wild-type $(\mathrm{C} 57+/+)$ and $m e / m e^{v}\left(\mathrm{Me}^{v}\right)$ mice were stained with biotinylated anti-CD5 antibody followed by streptavidin-FITC, and then subjected to flow cytometry.

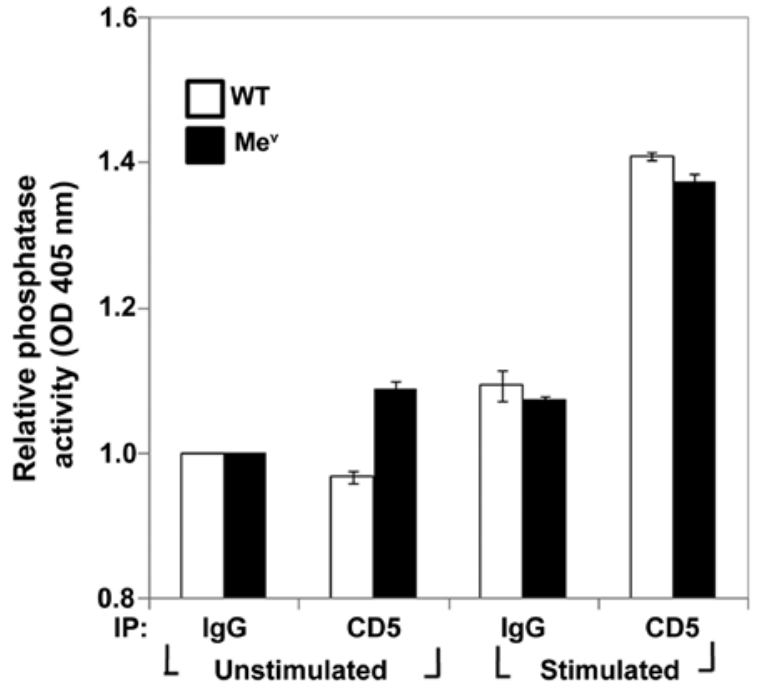

Figure 4. SHP-1 deficiency does not significantly alter CD5-associated PTP activity. Equal amounts of lysate prepared from unstimulated or stimulated (biotinylated anti-T-cell antigen receptor (TCR)/anti-CD4 plus streptavidin for $5 \mathrm{~min}$ at $\left.37^{\circ} \mathrm{C}\right)$ wild-type $(\mathrm{C} 57+/+)$ and $m e / m e^{v}\left(\mathrm{Me}^{v}\right)$-derived thymocytes $\left(1 \times 10^{8}\right)$ was subjected to immunoprecipitation using IgG control or anti-CD5 $\mathrm{mAb}$. Immunoprecipitates were then incubated in phosphatase buffer at $37^{\circ} \mathrm{C}$ for 90 min with $1 \mathrm{mM}$ phosphopeptide (RRLIEDAEY-pAARG). To standardize for the non-specific phosphatase activity associated with IgG, the relative phosphatase activity was determined by dividing the measured absorbance values with those from the unstimulated $\operatorname{IgG}$ negative controls.

and function. One of the earliest biochemical events to occur following TCR stimulation is the enhanced mobilization of calcium (35-38). Studies examining CD5 function have identified an important role for CD5 signaling in the calcium pathway $(11,15)$. Peripheral T-cell co-stimulation through antiCD5 antibodies has been shown to increase TCR/CD3-induced intracellular $\mathrm{Ca}^{2+}$ concentration (39), and this increase is entirely due to an influx of extracellular calcium (40-42). By contrast, $\mathrm{CD} 5$ acts as a negative regulator of antigen receptor-mediated calcium mobilization in thymocytes and B-1 cells $(15,29)$ since thymocytes and B-1 cells from CD5-deficient mice exhibit a moderate increase in $\mathrm{Ca}^{2+}$ mobilization following antigen receptor activation $(15,29)$. The differences suggest that $\mathrm{CD} 5$ possesses a dual function, providing either positive or negative modulatory signals depending on the cell type and maturational stage (43). However, the calcium mobilization profiles associated with CD5 and antigen receptor stimulation depend on the method of antibody crosslinking. In particular, co-crosslinking the antigen-receptor with CD5 compared to a separate crosslinking of the two receptors generates a qualitatively different calcium mobilization profile that can be explained in a manner consistent with a negative regulatory function for CD5 $(21,30,31)$.

Therefore, to examine the functional contribution of SHP-1 in $\mathrm{CD}$ /TCR-mediated $\mathrm{Ca}^{2+}$ mobilization, we produced a stimulation protocol based on those studies (Fig. 5). As shown in the top panel of Fig. 5, TCR crosslinking induces a rapid recruitment of CD5 to the TCR/CD3 complex, as has already been demonstrated by co-capping studies (44). Similarly, the coligation of TCR and CD5 resulted in a similar or increased recruitment of CD5 to the TCR complex (Fig. 5, middle panel), as this treatment has been reported to reduce the $\mathrm{Ca}^{2+}$ influx when compared to the ligation of TCR/CD3 alone (21). By contrast, when the TCR and CD5 were separately cross linked (Fig. 5, bottom panel) the recruitment of CD5 to the TCR complex was inhibited or significantly decreased (44). In keeping with the negative role of CD5, separate crosslinking of the antigen receptor and $\mathrm{CD} 5$ has been demonstrated to increase the $\mathrm{Ca}^{2+}$ mobilization and proliferative response in $\mathrm{B}-1$ cells, and this has been explained to occur as a result of CD5 sequestration from the BCR $(29,30)$. We hypothesized that if SHP-1 is required in the CD5-mediated calcium mobilization pathway, then the lack of SHP-1 activity may significantly affect the calcium influx profiles in thymocytes from SHP-1-deficient $m e^{v}$ compared to wild-type mice. As expected, the co-ligation of TCR and CD5 resulted in a slightly decreased or unchanged calcium influx in wild-type thymocytes when compared to the ligation of TCR alone (Figs. 6A and 5). Similarly, the inhibitory effects of CD5 were intact and readily observable in the $m e^{v}$ mice (Fig. 6B). Although, the initial upswing in calcium influx occurred at relatively the same time after the addition of the crosslinking agent $(\sim 40 \mathrm{sec})$, there was a definite decrease in the slope and amount of $\mathrm{Ca}^{2+}$ influx in thymocytes from SHP-1-deficient mice following CD5 and TCR coligation versus TCR ligation alone (Fig. $6 \mathrm{~B}$ ), suggesting that the CD5 receptor retains functionality even in the absence of SHP-1 

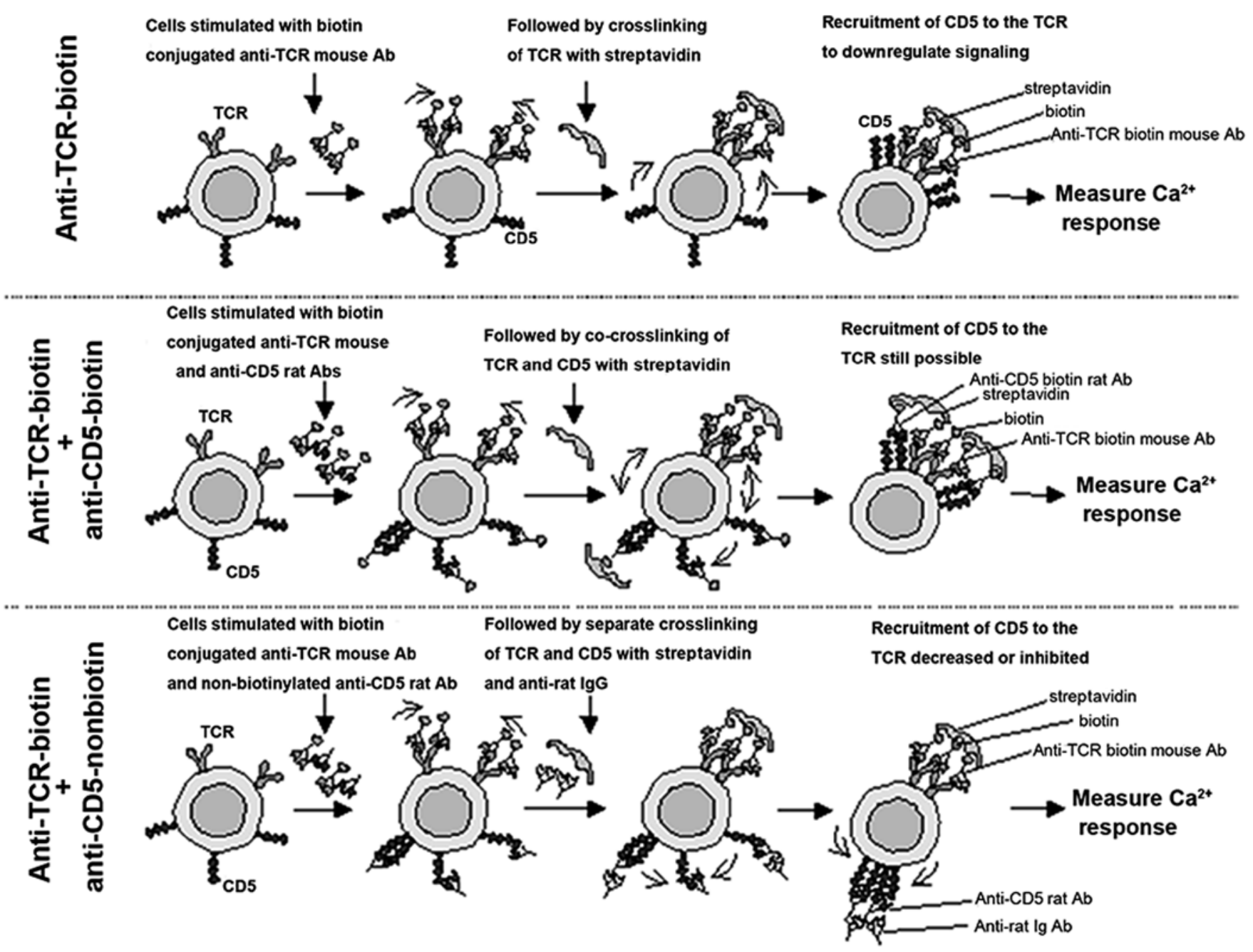

Figure 5. Stimulation protocol utilized for T-cell antigen receptor (TCR)/CD5-mediated calcium response. Indo-1-loaded thymocytes were incubated with biotinylated anti-TCR mouse Ab alone (top panel), or together with biotinylated anti-CD5 rat Ab (middle panel), or with non-biotinylated anti-CD5 rat Ab (lower panel). After TCR receptor crosslinking (top panel), TCR/CD5 receptor co-crosslinking (middle panel), or separate crosslinking of TCR/CD5 (bottom panel) calcium mobilization was recorded. As shown above, only in the instance of separate crosslinking of TCR and CD5 receptors (bottom panel) is the recruitment of CD5 to the TCR potentially affected to the greatest degree. Crosslinking was achieved using either streptavidin alone or with anti-rat IgG.

activity. We also examined, whether the calcium mobilization in thymocytes could be enhanced by sequestering or inhibiting the recruitment of CD5 to the antigen receptor complex (Fig. 5), as previously demonstrated by Sen et al in B-1 cells (30). The separate crosslinking of the TCR and CD5 resulted in a moderate increase in calcium mobilization, as witnessed by a definite change in the slope and amount of $\mathrm{Ca}^{2+}$ influx, in the wild-type and $m e^{v}$ thymocytes when compared to the ligation of TCR alone (Fig. 6C and D). Our results support a negative regulatory role for CD5 in thymocytes, which is consistent with the observations made in CD5-deficient thymocytes (15), and addresses the involvement of SHP-1 in CD5 signaling.

CD5 levels influence positive and negative selection in the thymus. A selection in thymocytes from CD5-deficient, $\alpha / \beta$-TCR transgenic mice has been shown to be altered in a manner consistent with enhanced TCR signaling (15). As another tool for exploring the functional and physiological role of CD5 in thymocyte development, Azzam et al (3) generated transgenic mice in which there is a $\mathrm{T}$ cell-specific, $\mathrm{CD} 2$ promoter/enhancer driven CD5 overexpression (CD5OE). CD5 surface expression in thymocytes from CD5OE mice have an $\sim 2.5$-fold increase in CD5 expression as compared to wild-type mice (Fig. 7). This increase in CD5 surface expression does not alter the kinetics of TCR-mediated CD5 phosphorylation, except for the observed increase in intensity of CD5 phosphorylation which is explained by the increase in CD5 protein levels (Fig. 7B). This observation suggests that the increased CD5 in the CD5OE mice is fully functional and participates in the CD5 signaling pathway. The CD5OE mice were previously bred onto the H-Y TCR transgenic background and shown to manifest a decrease in the positive and negative selection, thus corroborating the inhibitory role for CD5 in modulating signaling thresholds in T-cell selection (26).

One of the physiologically relevant functions of CD5 is to modulate TCR-mediated signals involved in T-cell development (3). Thus, we examined the ability of CD5 to modulate the selection process in the absence of SHP-1 activity to establish the physiological relevance of SHP-1 in CD5 signaling. In addition to other authors, we previously identified a role for SHP-1 in raising the signaling threshold required for both positive and negative selection $(26,34)$. Since CD5 and 

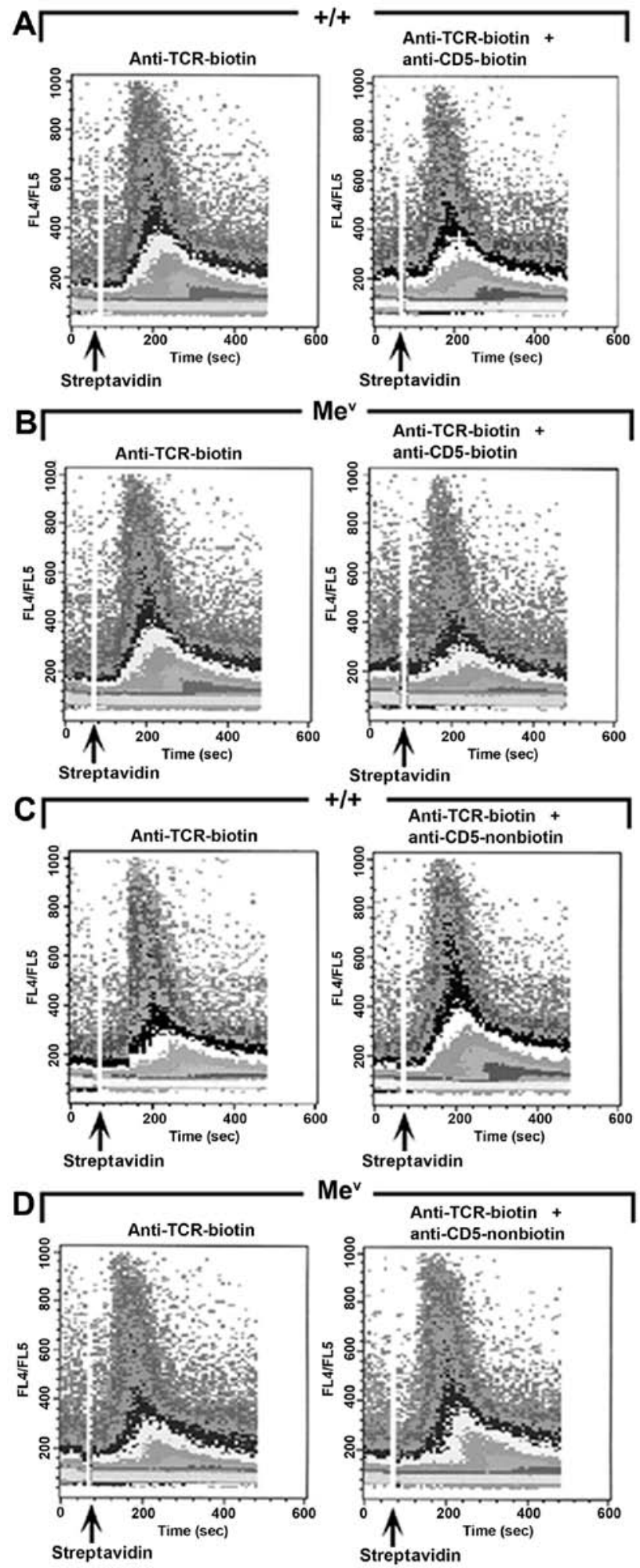

Figure 6. T-cell antigen receptor (TCR)/CD5-mediated calcium response is dependent on the method of CD5 stimulation. Co-aggregation of CD5 with TCR results in a reduced calcium response in wild-type (+/+) and in SHP-1-deficient $\left(m e^{v}\right)$ thymocytes. (A) Indo-1-loaded $(\mathrm{C} 57+/+)$ or (B) $m e / m e^{v}$ $\left(\mathrm{Me}^{v}\right)$ thymocytes were incubated with $2.0 \mu \mathrm{g}$ of biotinylated anti-TCR mouse $\mathrm{Ab}$ or together with $2.5 \mu \mathrm{g}$ of biotinylated anti-CD5 rat Ab, followed by surface receptor cross-linking with streptavidin $(5 \mu \mathrm{g})$. Separate cross-linking of CD5 with TCR results in an increase of the calcium response in wild-type $(+/+)$ and in SHP-1-deficient $\left(m e^{v}\right)$ thymocytes. (C) Indo-1-loaded wild-type $(\mathrm{C} 57+/+)$ or (D) $m e / m e^{v}\left(\mathrm{Me}^{v}\right)$ cells were incubated with $0.3 \mu \mathrm{g}$ of biotinylated anti-TCR Ab or together with $2.5 \mu \mathrm{g}$ of non-biotinylated anti-CD5 Ab, followed by surface receptor cross-linking with streptavidin $(5 \mu \mathrm{g})$. In all cases basal level calcium mobilization was recorded using flow cytometry for 1 min prior to crosslinking with streptavidin (arrows), followed by an additional $7 \mathrm{~min}$ of recording.
SHP-1 downregulate signals involved in T-cell selection, we hypothesized that CD5 overexpression would not be able to downregulate selection in the absence of SHP-1 activity, if SHP-1 is essential for CD5 function.

Positive selection is decreased in wild-type and SHP-1 deficient CD5OE H-Y transgenic females. As shown earlier [Zhang et al (26), unpublished data] , the inhibitory effect of CD5 overexpression (CD5OE) on positive selection was readily detected in female thymocytes from $\mathrm{H}-\mathrm{Y}$ TCR/CD5OE compared to HY-TCR transgenic mice (Fig. 8, upper panel). CD5 overexpression results in an increase in the representation of DP cells as well as a decrease in the number of SP CD8 ${ }^{+}$cells. The overexpression of CD5 in SHP-1-deficient $m e^{v}$ H-Y TCR transgenic mice also increased the size of the DP population and decreased the number of SP $\mathrm{CD}^{+}$cells compared to $m e^{v}$ H-Y TCR transgenic mice (Fig. 8, lower panel). Therefore, the lack of SHP-1 activity does not impact on the ability of CD5 to increase the threshold for TCR signaling. This finding provides evidence in favor of an SHP-1-independent CD5 receptor capable of downregulating positive selection.

Negative selection is decreased in wild-type and SHP-1 defcient CD5OE H-Y transgenic males. As previously shown (26), the inhibitory effect of CD5 overexpression (CD5OE) on negative selection was also readily detected in the current study, as revealed by the increased representation of DP and SP CD8 ${ }^{+}$cells in the thymuses of $\mathrm{H}-\mathrm{Y}$ TCR/CD5 compared to H-Y TCR mice (Fig. 9, upper panel). Nevertheless, we previously showed that the introduction of the $m e^{v}$ mutation nullifies the effects of CD5 overexpression, suggesting that SHP-1 deficiency is able to counteract the inhibitory effects of CD5 overexpression on negative selection (26), and raising the possibility that SHP-1 activity is required for CD5 to realize its inhibitory effects on negative selection. Careful re-examination of these data in light of the findings presented above for positive selection, suggests that the lack of any obvious and marked decrease in negative selection conferred by CD5 overexpression is due to the inability of CD5 to compensate for the increased signaling (and negative selection) inherent in SHP-1 deficiency, rather than due to a lack of CD5 function. Supporting this hypothesis is the finding that negative selection in the thymi of $m e^{v} \mathrm{H}-\mathrm{Y}$ TCR/CD5OE transgenic mice reveal a slight, albeit reproducible increase in the DP and SP CD4 ${ }^{\text {thi }}$ populations when compared with $m e^{v} \mathrm{H}-\mathrm{Y}$ TCR mice (Fig. 9 lower panel). The rescue of SP CD4 ${ }^{+}$cells observed in the $m e^{v} \mathrm{H}-\mathrm{Y}$ TCR mice is noteworthy, particularly in light of the study by Page, which found that CD5 was able to block MHC class II-dependent negative selection of $\mathrm{CD}^{+}$cells rather than $\mathrm{CD}^{+}$cells. The findings suggest that the effects of CD5 may be less profound on MHC class I-dependent negative selection (45). It is therefore possible that the enhanced TCR signaling imbued by SHP-1 deficiency (26), results in the initial rescue of a small population of $\mathrm{CD}^{+}$cells (even in the absence of MHC class II antigen presentation) manifesting the appropriate signals necessary for positive selection. Subsequently, a majority of these cells undergo negative selection for the same reasons as outlined above and it is only with $\mathrm{CD} 5$ overexpression that this $\mathrm{CD}^{+}$population is rescued in the $m e^{v} \mathrm{H}-\mathrm{Y}$ TCR male mice (Fig. 9). One explanation for this 


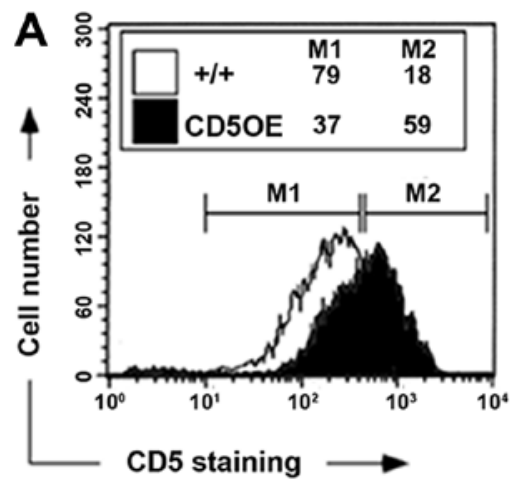

B

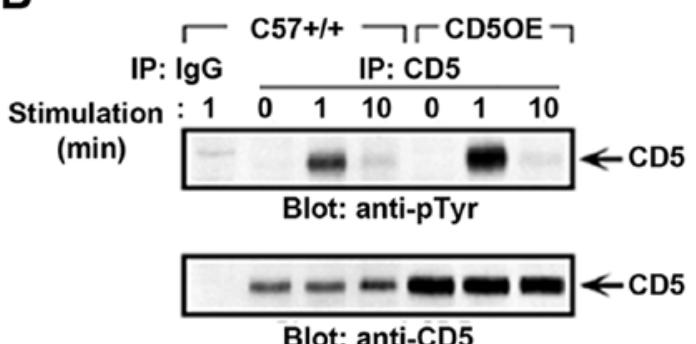

Blot: anti-CD5

Figure 7. The surface expression, phosphorylation and protein profiles of CD5 in wild-type (+/+) versus the CD5OE thymocytes. (A) Histogram showing the surface expression of CD5 in thymocytes $\left(5 \times 10^{6}\right)$ from wild-type $\left(\right.$ C5 $\left.7^{+/+}\right)$and CD5-overexpressing (CD5OE) mice stained with biotinylated anti-CD5 antibody followed by streptavidin-FITC, and then subjected to flow cytometry. (B) Immunoblot showing phosphorylation and protein expression profiles of CD5 in thymocytes $\left(3 \times 10^{7}\right)$ from wild-type $(\mathrm{C} 57+/+)$ and CD5-overexpressing (CD5OE) mice incubated with biotin-conjugated anti-mouse T-cell antigen receptor (TCR) and then stimulated by crosslinking with streptavidin for the indicated times. Equalized lysate proteins were then immunoprecipitated with control IgG or anti-CD5 mAb, resolved on 10\% sodium dodecyl sulfate-polyacrylamide gel electrophoresis (SDS-PAGE) and transferred to the membrane. The level of CD5 phosphorylation was detected by blotting with anti-phosphotyrosine antibody and the level of CD5 protein was determined by reprobing the blots with anti-CD5 (upper and lower panels, respectively).
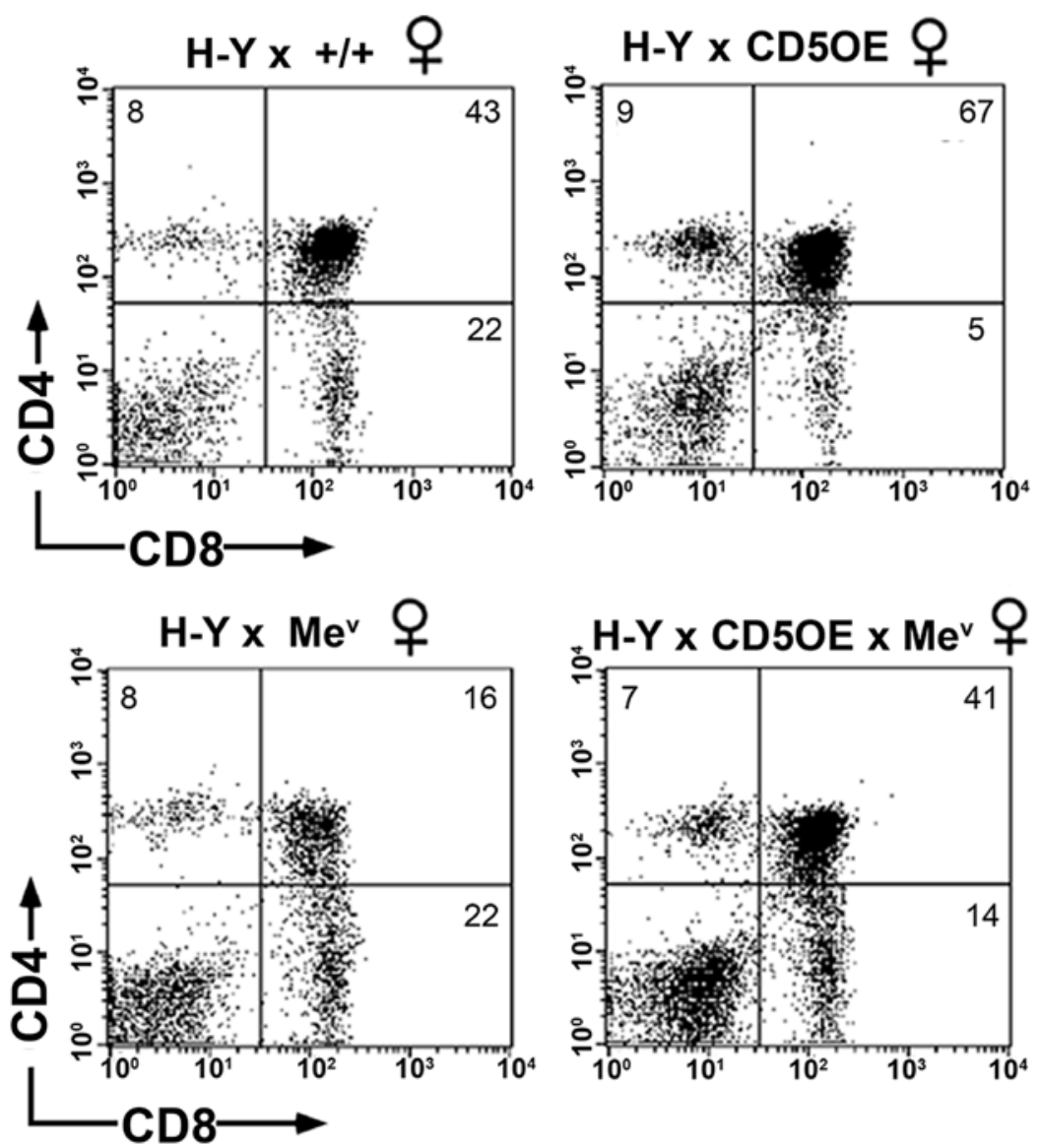

Figure 8. CD5 overexpression affects positive selection. Positive selection is decreased in both CD5OE HY T-cell antigen receptor (TCR) and CD5OE HY TCR $m e^{v}$ transgenic females. CD4 and CD8 expression in thymocytes from wild-type, CD5-overexpressing (CD5OE), SHP-1-deficient and SHP-1-deficient CD5-overexpressing (CD5OE) transgenic female mice. Thymocytes from female H-Y TCR (H-Y x +/+) and H-Y TCR CD5-overexpressing (H-Y x CD5OE) mice (upper panel) or from female $m e^{v} / m e^{v} \mathrm{H}-\mathrm{Y}$ TCR $\left(\mathrm{H}-\mathrm{Y} \times \mathrm{Me}^{v}\right.$ ) and $m e^{v} / m e^{v} \mathrm{H}-\mathrm{Y}$ TCR CD5-overexpressing (H-Y x CD5OE x Me ${ }^{v}$ ) mice (lower panel) were stained with anti-CD8-FITC and anti-CD4-PE and then subjected to flow cytometry. The parameter histograms show CD4 and CD8 expression with percentages of stained cells indicated in each quadrant. The results are representative of five independent experiments.

result is that when the analysis is restricted to a clonotypic TCR, a partial reduction in signaling ability readily decreases the signals from the positive selection interactions below the required threshold. By contrast, when the negative selection stimulus is strong enough, a partial reduction in signaling ability may not be sufficient to interfere with this process. 

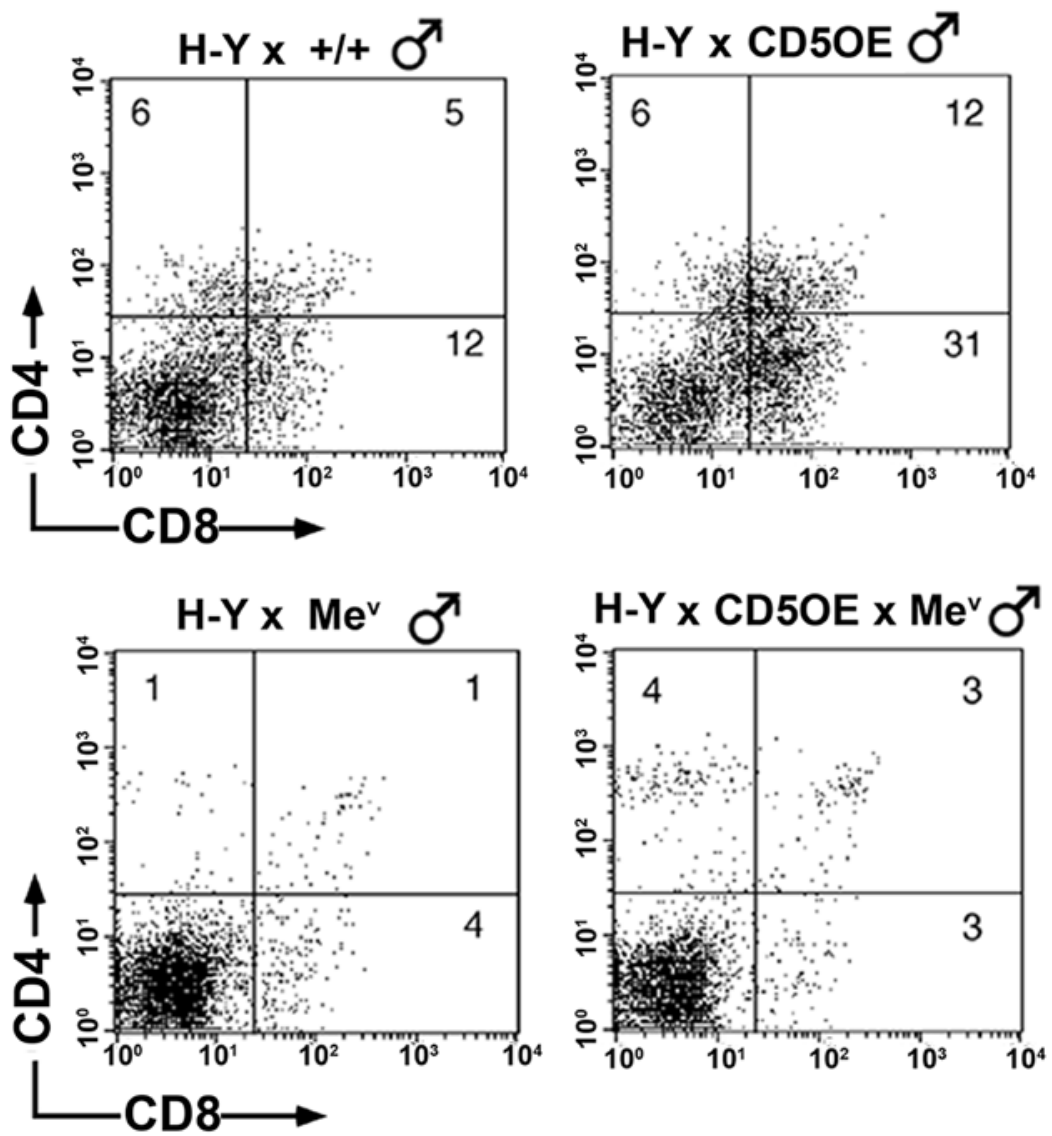

Figure 9. CD5 overexpression affects negative selection. Negative selection is decreased in CD5OE HY T-cell antigen receptor (TCR) and CD5OE HY TCR $m e^{v}$ transgenic males. CD4 and CD8 expression in thymocytes from wild-type, CD5-overexpressing (CD5OE), SHP-1-deficient and SHP-1-deficient CD5-overexpressing (CD5OE) transgenic male mice. Thymocytes from male H-Y TCR (H-Y x +/+) and H-Y TCR CD5-overexpressing (H-Y x CD5OE) mice (upper panel) or from male $m e^{v} / m e^{v} \mathrm{H}-\mathrm{Y}$ TCR $\left(\mathrm{H}-\mathrm{Y} \times \mathrm{Me}^{v}\right)$ and $m e^{v} / m e^{v} \mathrm{H}-\mathrm{Y}$ TCR CD5-overexpressing (H-Y x CD5OE x Me $)$ mice (lower panel) were stained with anti-CD8-FITC and anti-CD4-PE and then subjected to flow cytometry. The parameter histograms show CD4 and CD8 expression with percentages of stained cells indicated in each quadrant. The results are representative of five independent experiments.

Thus, CD5 effects on positive and negative T-cell selection are realized independently of SHP-1.

\section{Discussion}

The role of CD5 signaling and function remains elusive, although considerable evidence favors a negative regulatory role for CD5 in thymocyte and B-1 cell signaling (13). Previous results have identified and implicated several cell effectors in the CD5 signaling pathway. For instance, in B cells CD5 constitutively induces multiple signaling pathways such as extracellular signal-regulated kinases (ERK1/2), phosphatidylinositol 3-kinase (PI3K)/mammalian target of rapamycin (mTOR) and calcineurin-NFAT signaling pathways (46). However, the physiological and functional relevance of these pathways to CD5 function are not completely understood.

The majority of studies examining the role of SHP-1 in CD5 signaling have been carried in vitro. To the best of our knowledge, this is the first study to examine the relevance of SHP-1 in CD5 signaling, by utilizing primary thymocytes from SHP-1-deficient $m e^{v}$ mice. Furthermore, given that CD5 and SHP-1 negatively regulate thymocyte development $(26,47)$, we have utilized an H-Y TCR/CD5-overexpressing mouse model to elucidate the physiological and functional importance of SHP-1 for mediating CD5-induced downregulation of both positive and negative selection.

Given that the association of SHP-1 is increased following CD5 phosphorylation, suggests an SH2-mediated binding mechanism. The cytoplasmic domain of CD5 contains an ITAM-like sequence, as well as sequences similar to motifs proposed as SHP-1 binding sites (47). By contrast, studies by Gary-Gouy et al (31) and Peña-Rossi et al (16) assessed the importance of SHP-1 association for CD5 function. When Tyr-378 within the ITIM-like sequence is omitted from the CD5 chimera, the negative regulatory functions of CD5 were unaffected despite any observable association with SHP-1. Similarly, CD5-deficient T-cell hybridomas transfected with a truncated form of CD5 that retained the ITIM-like sequence (Y378) were unable to negatively regulate TCR responses or associate with SHP-1 (16). The findings suggest that the ITIM-like sequence is not required for CD5 function as well as questions the direct requirement of SHP-1 in the CD5 pathway. Based on these findings, the interaction of SHP-1 with CD5 may be indirect through other proteins that are recruited to phosphorylated CD5. For example p56 Lck and the p85 regulatory subunit of PI3K have been shown to associate with phosphorylated CD5 folloiwng TCR activation as well as SHP-1 (48-50). 
The reported interaction of SHP-1 with CD5 has led to the speculation that CD5 is a substrate for CD5 activity. In particular, studies examining CD2 and CD3 signaling in Jurkat $\mathrm{T}$ cells found that the activity of SHP-1 increased following CD2 stimulation and decreased following TCR/CD3 activation (22). Furthermore, this change in SHP-1 activity correlated with the CD5 phosphorylation status, suggesting that SHP-1 may specifically dephosphorylate CD5 (22). However, we did not detect any significant changes in the CD5 phosphorylation profile of SHP-1-deficient mice suggesting that SHP-1 is not the sole or major phosphatase responsible for CD5 dephosphorylation.

Gary-Gouy et al in B lymphoma cell lines suggested that the effect of CD5 at least on BCR signaling, is independent of SHP-1 (31). In order to determine whether SHP-1 is the major phosphatase associated with CD5 in thymocytes, we immunoprecipitated CD5 from resting and TCR-stimulated thymocytes from both normal and SHP-1 deficient $\left(m e^{v}\right)$ mice. Our results suggest that the in vitro phosphatase activity associated with CD5 is unaffected by SHP-1 deficiency. In agreement with data from Gary-Gouy et al (31) and PeñaRossi et al (16), our findings, in thymocytes, also shed light on the importance of SHP-1 activity for CD5 function. The presence of CD5-associated PTP activity in $m e^{v}$ suggests that there is a redundancy with respect to SHP-1 function, or more likely, there are other phosphatases capable of mediating the negative modulatory effects of CD5.

To establish the functional importance of SHP-1 to CD5-mediated negative signaling we examined the ability of CD5 to modulate TCR-induced calcium mobilization profiles. We employed a stimulation protocol (Fig. 5) designed to assess whether the CD5 modulation of $\mathrm{Ca}^{2+}$ influx is preserved despite SHP-1 deficiency. The findings demonstrate that even in the absence of SHP-1 activity we can elicit changes in calcium mobilization profiles consistent with that of a functioning CD5 receptor. These results support the involvement of $\mathrm{CD} 5$ in $\mathrm{Ca}^{2+}$ mobilization, as previously shown (51). Our stimulation protocol suggests that the method of CD5 stimulation lead to differential effects in thymocytes at least at the level of calcium mobilization. It is noteworthy to determine whether this differential effect of CD5, which most likely results from whether CD5 is recruited or sequestered away from the antigen receptor, has a physiological impact. In this regard, it is of note that two recent studies examining thymic selection utilizing the same anti-CD5 antibody (53-7.3) in their studies attribute differing roles for CD5 in the negative selection $(45,52)$. The study by Kishimoto and Sprent demonstrates that CD5 costimulation is required for efficient negative selection (52), while Page demonstrates that CD5 prevents or reduces negative selection (45). Although these studies do not address the mechanism for their observed results, Kishimoto and Sprent's experimental model CD5 (52) was presented in a cross-linked form (i.e, in precoated wells), while in Page's model CD5 was presented in an unbound form (45). Consistent with the negative regulatory role for CD5 in thymocytes, the observed differences in the two studies can be explained by the following model. In the study by Kishimoto and Sprent, CD5 crosslinking to the well possibly prevents the recruitment of CD5 to the TCR resulting in enhanced signaling leading to increased negative selection (52). By contrast, in Page's study, although bound to anti-CD5 antibody, CD5 remained unanchored and free to associate with the TCR and was able to downregulate negative selection (45). Furthermore, it is possible that the anti-CD5 antibody, by blocking the interactions of CD5 with physiological ligands such as CD5L (53), prevents the sequestration of CD5 away from the TCR.

Given that CD5 expression is developmentally regulated by the strength and avidity of TCR signals (3), we examined whether the thymic expression levels of CD5 were affected in $m e^{v}$ compared to wild-type mice. Although we did not observe any changes in thymic CD5 surface expression levels, the reported elevation of CD5 in SHP-1-deficient peripheral T cells is noteworthy (34). The elevation in CD5 surface levels in light of SHP-1 deficiency suggests that CD5 may be functioning to provide a compensatory mechanism for maintaining steadystate levels of TCR signaling (34). This compensatory model is further supported by the finding that Vav-deficient mice, in which TCR signaling is inefficient, express low surface levels of CD5 (34,54,55).

Given the importance of CD5 during T-cell development we determined whether the effects of CD5 overexpression were maintained in the absence of SHP-1. The results, were in agreement with previous studies, demonstrating a role for CD5 in downregulating the positive and negative selection $(15,16)$, and reveal that CD5 overexpression reduces positive and negative selection in wild-type and $m e^{v}$ mice. The ability of the overexpressed $\mathrm{CD} 5$ to decrease the $\mathrm{SP} \mathrm{CD} 8{ }^{+}$population in SHP-1-deficient H-Y TCR females indicates that CD5 retains an inhibitory function and is able to increase the signaling threshold for positive selection. Although the inhibitory effects of CD5 overexpression during negative selection in $m e^{v}$ thymocytes is not as apparent as that observed in wild-type or positive selection. This is not surprising given that signaling thresholds play a vital role during thymic selection. In this regard, the TCR signals transduced during the negative selection were much stronger than those in the positive selection providing a mechanism for the deletion of self-reactive thymocytes. Therefore, given the dominant role SHP-1 occupies in downregulating TCR signals, the lack of SHP-1 reduces the signaling threshold considerably, thereby increasing the strength of TCR signals in general and in particular during negative selection. It is therefore highly unlikely that in this context, the inhibitory actions of overexpressed CD5 may be effective to the same degree in reducing negative selection. Therefore, our observation is likely to reflect the inability of CD5 to compensate for the increased signaling inherent in SHP-1 deficiency rather than a lack of CD5 function (26).

In the present study, we have examined the functional and physiological requirement of SHP-1 in the CD5 signaling pathway. The results show that although SHP-1 can associate with $\mathrm{CD} 5$, the tyrosine phosphorylation profile of CD5 following TCR stimulation is no different in SHP-1-deficient viable motheaten $\left(m e^{v}\right)$ compared to wild-type thymocytes. The lack of SHP-1 activity also had no impact on levels of CD5 surface expression, CD5-associated PTP activity, and intracellular calcium mobilization profiles following TCR/CD5 co-crosslinking. Similarly, an analysis of T-cell thymocyte populations in $m e^{v}$ mice expressing an H-Y transgene as well as a construct mediating T-cell restricted CD5 overexpression, revealed that the reduction in selection conferred by CD5 over- 
expression was unaffected by SHP-1 deficiency. Cumulatively, these observations indicate that CD5 is not a SHP-1 substrate and suggest SHP-1 is not required for and possibly not involved in CD5-mediated downregulation of TCR signaling. By using an in vitro stimulation protocol that crosslinks CD5/TCR together or separately, we have also demonstrated a differential effect of CD5, at least on TCR-mediated calcium influx.

\section{Acknowledgements}

The authors thank Giselle Knowles and Lingli Ma for technical assistance and Denis Bouchard for assistance with immunofluorescence analysis.

\section{References}

1. Martínez VG, Moestrup SK, Holmskov U, Mollenhauer J and Lozano F: The conserved scavenger receptor cysteine-rich superfamily in therapy and diagnosis. Pharmacol Rev 63: 967-1000, 2011.

2. Mandl JN, Monteiro JP, Vrisekoop N and Germain RN: $\mathrm{T}$ cell-positive selection uses self-ligand binding strength to optimize repertoire recognition of foreign antigens. Immunity 38 : 263-274, 2013

3. Azzam HS, Grinberg A, Lui K, Shen H, Shores EW and Love PE: CD5 expression is developmentally regulated by $\mathrm{T}$ cell receptor (TCR) signals and TCR avidity. J Exp Med 188: 2301-2311, 1998

4. Stamou P, de Jersey J, Carmignac D, Mamalaki C, Kioussis D and Stockinger B: Chronic exposure to low levels of antigen in the periphery causes reversible functional impairment correlating with changes in CD5 levels in monoclonal CD8 T cells. J Immunol 171: $1278-1284,2003$

5. Raman C: CD5, an important regulator of lymphocyte selection and immune tolerance. Immunol Res 26: 255-263, 2002.

6. Klinker MW and Lundy SK: Multiple mechanisms of immune suppression by B lymphocytes. Mol Med 18: 123-137, 2012.

7. Mage RG and Pospisil R: CD5 and other superantigens may select and maintain rabbit self-renewing B-lymphocytes and human B-CLL cells. Curr Top Microbiol Immunol 252: 87-96, 2000.

8. Mamonkin M, Rouce RH, Tashiro H and Brenner MK: A T-cell-directed chimeric antigen receptor for the selective treatment of T-cell malignancies. Blood 126: 983-992, 2015.

9. Sheng JR, Quan S and Soliven B: CDld(hi)CD5 ${ }^{+}$B cells expanded by GM-CSF in vivo suppress experimental autoimmune myasthenia gravis. J Immunol 193: 2669-2677, 2014.

10. Beaudette-Zlatanova BC, Le PT, Knight KL, Zhang S, Zakrzewski S, Parthasarathy M and Stiff PJ: A potential role for $\mathrm{B}$ cells in suppressed immune responses in cord blood transplant recipients. Bone Marrow Transplant 48: 85-93, 2013.

11. Spertini F, Stohl W, Ramesh N, Moody C and Geha RS: Induction of human T cell proliferation by a monoclonal antibody to CD5. J Immunol 146: 47-52, 1991.

12. Alberola-Ila J, Places L, Cantrell DA, Vives J and Lozano F: Intracellular events involved in CD5-induced human T cell activation and proliferation. J Immunol 148: 1287-1293, 1992.

13. Ochi $\mathrm{H}$ and Watanabe T: Negative regulation of $\mathrm{B}$ cell receptormediated signaling in B-1 cells through CD5 and Ly49 co-receptors via Lyn kinase activity. Int Immunol 12: 1417-1423, 2000.

14. Fenutría R, Martinez VG, Simões I, Postigo J, Gil V, MartínezFlorensa M, Sintes J, Naves R, Cashman KS, Alberola-Ila J, et al: Transgenic expression of soluble human CD5 enhances experimentally-induced autoimmune and anti-tumoral immune responses. PLoS One 9: e84895, 2014.

15. Tarakhovsky A, Kanner SB, Hombach J, Ledbetter JA, Müller W, Killeen N and Rajewsky K: A role for CD5 in TCR-mediated signal transduction and thymocyte selection. Science 269: 535-537, 1995.

16. Peña-Rossi C, Zuckerman LA, Strong J, Kwan J, Ferris W, Chan S, Tarakhovsky A, Beyers AD and Killeen N: Negative regulation of CD4 lineage development and responses by CD5. J Immunol 163: 6494-6501, 1999.

17. Dennehy KM, Ferris WF, Veenstra H, Zuckerman LA, Killeen N and Beyers AD: Determination of the tyrosine phosphorylation sites in the $\mathrm{T}$ cell transmembrane glycoprotein CD5. Int Immunol 13: 149-156, 2001.
18. Iwai LK, Benoist C, Mathis D and White FM: Quantitative phosphoproteomic analysis of $\mathrm{T}$ cell receptor signaling in diabetes prone and resistant mice. J Proteome Res 9: 3135-3145, 2010.

19. Beyers AD, Spruyt LL and Williams AF: Molecular associations between the T-lymphocyte antigen receptor complex and the surface antigens CD2, CD4, or CD8 and CD5. Proc Natl Acad Sci USA 89: 2945-2949, 1992.

20. Unkeless JC and Jin J: Inhibitory receptors, ITIM sequences and phosphatases. Curr Opin Immunol 9: 338-343, 1997.

21. Perez-Villar JJ, Whitney GS, Bowen MA, Hewgill DH, Aruffo AA and Kanner SB: CD5 negatively regulates the T-cell antigen receptor signal transduction pathway: Involvement of SH2-containing phosphotyrosine phosphatase SHP-1. Mol Cell Biol 19: 2903-2912, 1999.

22. Carmo AM, Castro MA and Arosa FA: CD2 and CD3 associate independently with CD5 and differentially regulate signaling through CD5 in Jurkat T cells. J Immunol 163: 4238-4245, 1999.

23. Tibaldi E, Brunati AM, Zonta F, Frezzato F, Gattazzo C, Zambello R, Gringeri E, Semenzato G, Pagano MA and Trentin L: Lyn-mediated SHP-1 recruitment to CD5 contributes to resistance to apoptosis of B-cell chronic lymphocytic leukemia cells. Leukemia 25: 1768-1781, 2011.

24. Kisielow P, Blüthmann H, Staerz UD, Steinmetz M and von Boehmer H: Tolerance in T-cell-receptor transgenic mice involves deletion of nonmature $\mathrm{CD}^{+} 8^{+}$thymocytes. Nature 333 : 742-746, 1988.

25. Love PE, Shores EW, Lee EJ, Grinberg A, Munitz TI, Westphal H and Singer A: Differential effects of zeta and eta transgenes on early alpha/beta T cell development. J Exp Med 179: 1485-1494, 1994.

26. Zhang J, Somani AK, Yuen D, Yang Y, Love PE and Siminovitch KA: Involvement of the SHP-1 tyrosine phosphatase in regulation of $\mathrm{T}$ cell selection. J Immunol 163: 3012-3021, 1999.

27. Kozlowski M, Mlinaric-Rascan I, Feng GS, Shen R, Pawson T and Siminovitch KA: Expression and catalytic activity of the tyrosine phosphatase PTP1C is severely impaired in motheaten and viable motheaten mice. J Exp Med 178: 2157-2163, 1993.

28. Pani G, Fischer KD, Mlinaric-Rascan I and Siminovitch KA: Signaling capacity of the $\mathrm{T}$ cell antigen receptor is negatively regulated by the PTP1C tyrosine phosphatase. J Exp Med 184: 839-852, 1996.

29. Bikah G, Carey J, Ciallella JR, Tarakhovsky A and Bondada S: CD5-mediated negative regulation of antigen receptor-induced growth signals in B-1 B cells. Science 274: 1906-1909, 1996.

30. Sen G, Bikah G, Venkataraman C and Bondada S: Negative regulation of antigen receptor-mediated signaling by constitutive association of CD5 with the SHP-1 protein tyrosine phosphatase in B-1 B cells. Eur J Immunol 29: 3319-3328, 1999.

31. Gary-Gouy H, Bruhns P, Schmitt C, Dalloul A, Daëron M and Bismuth G: The pseudo-immunoreceptor tyrosine-based activation motif of CD5 mediates its inhibitory action on B-cell receptor signaling. J Biol Chem 275: 548-556, 2000.

32. Dennehy KM, Broszeit R, Ferris WF and Beyers AD: Thymocyte activation induces the association of the proto-oncoprotein $\mathrm{c}-\mathrm{cbl}$ and ras GTPase-activating protein with CD5. Eur J Immunol 28: 1617-1625, 1998.

33. Weiss A, Dazin PF, Shields R, Fu SM and Lanier LL: Functional competency of $\mathrm{T}$ cell antigen receptors in human thymus. J Immunol 139: 3245-3250, 1987.

34. Johnson KG, LeRoy FG, Borysiewicz LK and Matthews RJ: TCR signaling thresholds regulating $\mathrm{T}$ cell development and activation are dependent upon SHP-1. J Immunol 162: 3802-3813, 1999.

35. Imboden JB, Weiss A and Stobo JD: The antigen receptor on a human $T$ cell line initiates activation by increasing cytoplasmic free calcium. J Immunol 134: 663-665, 1985.

36. Imboden JB and Stobo JD: Transmembrane signalling by the $\mathrm{T}$ cell antigen receptor. Perturbation of the T3-antigen receptor complex generates inositol phosphates and releases calcium ions from intracellular stores. J Exp Med 161: 446-456, 1985.

37. Ledbetter JA, June CH, Martin PJ, Spooner CE, Hansen JA and Meier KE: Valency of CD3 binding and internalization of the CD3 cell-surface complex control $\mathrm{T}$ cell responses to second signals: Distinction between effects on protein kinase C, cytoplasmic free calcium, and proliferation. J Immunol 136: 3945-3952, 1986.

38. Altman A, Coggeshall KM and Mustelin T: Molecular events mediating T cell activation. Adv Immunol 48: 227-360, 1990.

39. Hardy RR and Hayakawa K: Development and physiology of Ly-1 B and its human homolog, Leu-1 B. Immunol Rev 93: 53-79, 1986. 
40. June $\mathrm{CH}$, Rabinovitch PS and Ledbetter JA: CD5 antibodies increase intracellular ionized calcium concentration in $\mathrm{T}$ cells. J Immunol 138: 2782-2792, 1987.

41. Gupta S: Mechanisms of transmembrane signalling in human T cell activation. Mol Cell Biochem 91: 45-50, 1989.

42. Vandenberghe P, Verwilghen J, Van Vaeck F and Ceuppens JL: Ligation of the CD5 or CD28 molecules on resting human $\mathrm{T}$ cells induces expression of the early activation antigen CD69 by a calcium- and tyrosine kinase-dependent mechanism. Immunology 78: 210-217, 1993.

43. Simarro M, Calvo J, Vilà JM, Places L, Padilla O, Alberola-Ila J, Vives J and Lozano F: Signaling through CD5 involves acidic sphingomyelinase, protein kinase $\mathrm{C}$-zeta, mitogen-activated protein kinase kinase, and c-Jun NH2-terminal kinase. J Immunol 162: 5149-5155, 1999.

44. Osman N, Ley SC and Crumpton MJ: Evidence for an association between the T cell receptor/CD3 antigen complex and the CD5 antigen in human T lymphocytes. Eur J Immunol 22: 2995-3000, 1992 .

45. Page DM: Cutting edge: Thymic selection and autoreactivity are regulated by multiple coreceptors involved in $\mathrm{T}$ cell activation. J Immunol 163: 3577-3581, 1999.

46. Mageed RA, Garaud S, Taher TE, Parikh K, Pers JO, Jamin C, Renaudineau Y and Youinou P: CD5 expression promotes multiple intracellular signaling pathways in B lymphocyte. Autoimmun Rev 11: 795-798, 2012.

47. Amantini C, Mosca M, Lucciarini R, Perfumi MC and Santoni G: Thiorphan-induced survival and proliferation of rat thymocytes by activation of Akt/survivin pathway and inhibition of caspase-3 activity. J Pharmacol Exp Ther 327: 215-225, 2008.

48. Dennehy KM, Broszeit R, Garnett D, Durrheim GA, Spruyt LL and Beyers AD: Thymocyte activation induces the association of phosphatidylinositol 3-kinase and pp120 with CD5. Eur J Immunol 27: 679-686, 1997.
49. Cuevas B, Lu Y, Watt S, Kumar R, Zhang J, Siminovitch KA and Mills GB: SHP-1 regulates Lck-induced phosphatidylinositol 3-kinase phosphorylation and activity. J Biol Chem 274: 27583-27589, 1999.

50. Imani F, Rager KJ, Catipovic B and Marsh DG: Interleukin-4 (IL-4) induces phosphatidylinositol 3-kinase (p85) dephosphorylation. Implications for the role of SHP-1 in the IL-4-induced signals in human B cells. J Biol Chem 272: 7927-7931, 1997.

51. Antony P, Petro JB, Carlesso G, Shinners NP, Lowe J and Khan WN: B cell receptor directs the activation of NFAT and NF-kappaB via distinct molecular mechanisms. Exp Cell Res 291: 11-24, 2003.

52. Kishimoto H and Sprent J: Several differenT cell surface molecules control negative selection of medullary thymocytes. J Exp Med 190: 65-73, 1999.

53. Sanjurjo L, Amézaga N, Aran G, Naranjo-Gómez M, Arias L, Armengol C, Borràs FE and Sarrias MR: The human CD5L/AIM-CD36 axis: A novel autophagy inducer in macrophages that modulates inflammatory responses. Autophagy 11: 487-502, 2015 .

54. Turner M, Mee PJ, Walters AE, Quinn ME, Mellor AL, Zamoyska R and Tybulewicz VL: A requirement for the Rho-family GTP exchange factor Vav in positive and negative selection of thymocytes. Immunity 7: 451-460, 1997.

55. Tanaka Y, So T, Lebedeva S, Croft M and Altman A: Impaired IL-4 and c-Maf expression and enhanced Th1-cell development in Vav1-deficient mice. Blood 106: 1286-1295, 2005. 